1 Neafie RC, Piggot JP. Human pulmonary dirofilariasis. Arch Pathol 1971;92:342-9.

2 Fleisher AG, Messina JJ, Ryan SF, Hopkins KS. Human pulmonary dirofilariasis: does diagnosis require thoracotomy? Ann Thorac Surg 1988;45:447-8.

3 Yoshimura H, Yokogawa M. Dirofilaria causing infarct in human lung. Am J Trop Med Hyg 1970;19:63-7.

4 Robinson NB, Chavez CM, Conn JH. Pulmonary dirofilariasis in man. J Thorac Cardiovasc Surg 1977;74:403-8.
5 Dashiell GF. A case of dirofilariasis involving the lung. $A m \mathrm{~J}$ Trop Med Hyg 1961;10:37-8.

6 Ciferri F. Human pulmonary dirofilariasis in the United States: a critical review. Am J Trop Med Hyg 1982;31: 302-8.

7 Beaver PC, Orihel TC. Human infection with filariae of animals in the United States. Am J Trop Med Hyg 1965;14:1010-29.
Department of Thoracic Medicine, University of

Manchester School of

Medicine, Salford

Royal Hospital,

Salford M6 9EP

H K Makker

P C Barnes

Reprint requests to:

Dr H K Makker, Medicine 1,

Level D, Centre Block,

Southampton General

SO9 4XY

Accepted 15 April 1991

\section{Fatal haemoptysis from the pulmonary artery as a late complication of pulmonary irradiation}

\author{
H K Makker, P C Barnes
}

\begin{abstract}
Fatal massive haemoptysis occurred as a late complication of erosion of the pulmonary artery by a non-malignant ulcer of the left main bronchus.
\end{abstract}

Symptoms attributed to radiation pulmonary fibrosis are uncommon. ${ }^{1}$ We report a case of fatal massive haemoptysis in a patient known to have postirradiation pulmonary fibrosis.

\section{Case report}

In January 1990 a 69 year old man, an exsmoker, was admitted to hospital with a three week history of cough, purulent sputum, minor haemoptysis, and worsening dyspnoea. An inoperable bronchogenic carcinoma of the right upper lobe bronchus had been diagnosed in 1982 on the basis of a right hilar mass on the chest radiograph and bronchoscopic biopsy specimens described as "suspicious of carcinoma." In view of the proximity of the lesion to the mediastinum he was treated by radiotherapy with small field rotational treatment focused on the right hilum $(8 \times 8 \times 8 \mathrm{~cm}$; dosage $4250 \mathrm{cGy}$ in eight fractions over 10 days). The initial diagnosis was amended in 1985, however, a review of the initial bronchial biopsy material and subsequent biopsy specimens. On admission in 1990 he was dyspnoeic, centrally cyanosed, febrile $\left(37 \cdot 5^{\circ} \mathrm{C}\right)$, and drowsy. On examination of the chest the clinical and radiological signs (fig 1) were consistent with right upper lobe fibrosis. Laboratory investigations showed leucocytosis $\left(18.7 \times 10^{9} / 1\right.$ with $89 \%$ neutrophils. Sputum grew Staphylococcus aureus but blood cultures were sterile. $\mathrm{He}$ received appropriate antibiotics and supportive treatment. His sputum cleared and he had no further haemoptysis until during the second week of his hospital stay, when he was ready to be discharged, he had an unheralded and rapidly fatal massive haemoptysis.

Pathology At necropsy the left main bronchus showed an annular ulcer extending for two centimetres. There was an adherent clot at the base of the ulcer and a well demarcated area where the base of the ulcer had eroded into the underlying pulmonary artery. Microscopic examination of the ulcer showed focal necrosis and inflammatory infiltrates of the pulmonary artery, closely opposed adjacent cartilage with a narrow intervening zone of fibrosis and aggregates of inflammatory cells (fig $2 a$ ). The appearances were consistent with this being the site of haemorrhage. Adjacent branches of the pulmonary artery showed intimal proliferation, occlusion and recanalization changes consistent with chronic radiation damage (fig $2 b$ ). There was no evidence of malignancy, lung abscess, or aspergilloma.

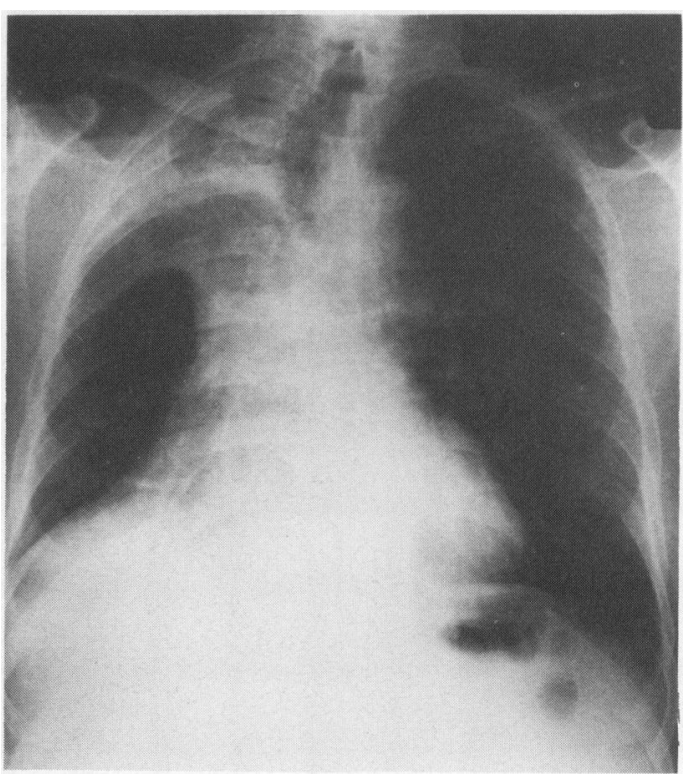

Figure 1 Chest radiograph showing postirradiation right upper lobe fibrosis. 



Figure 2 (a) Section showing edge of ulcer (U), bronchial wall (B) on right, and the pulmonary artery wall $(P)$ infiltrated by inflammatory cells and covered by slough (arrowed). (b) Section showing an area of fibrosis and pulmonary artery in the centre. The lumen of the artery is almost completely occluded by intimal proliferation.

\section{Discussion}

A few patients with pre-existing impairment of pulmonary function or in whom an extensive area of lung has been irradiated develop chronic respiratory failure. ${ }^{2}$ Massive haemoptysis from abnormal bronchial arteries has been reported as a late consequence of pul- monary irradiation ${ }^{3}$ and there are reports of aspergilloma, which can cause massive haemoptysis, complicating post-irradiation pulmonary fibrosis ${ }^{45}$ Although radiotherapy is widely used for lung tumours, few cases of haemoptysis have been reported as a late complication. This is probably due to poor survival as a consequence of the malignancy.

Irradiation can cause severe damage to all segments of the arterial wall. Marcial-Rojas $e t$ $a l^{6}$ and $\mathrm{McC}$ ready et $a l^{7}$ reported massive haemorrhage from large arteries after irradiation for neoplasm. In their series infection played an important part in arterial rupture. They also observed an initial minor bleeding episode followed by rupture of the artery. In our patient a respiratory tract infection and minor haemoptysis preceded the terminal haemoptysis by about two weeks. The infection may have precipitated the massive haemoptysis from an area of pre-existing damage caused by past irradiation. Although radiotherapy was focused on the right hilum, the rotational technique used necessitates irradiation of a large volume of lung. The non-malignant ulcer of the left main bronchus and changes in the surrounding lung parenchyma and pulmonary arteries are likely to have resulted from the radiotherapy. Bennett et $a l^{8}$ have described unusual cases of bilateral lung injury following unilateral radiation. Symptoms of respiratory tract infection and minor haemoptysis in patients with postirradiation fibrosis may represent warnings of massive haemoptysis.

1 Hellman S, Kligerman MM, von Essen CF, et al. Sequelae of radical radiotherapy of carcinoma of lung. Radiology 1964;82:1055-61.

2 Gross NJ. Pulmonary effects of radiation therapy. Ann Intern Med 1977;86:81-92.

3 Isaacs RD, White WJ, Wells AV, Rea HH, Bai TR. Massive haemoptysis as a late consequence of pulmonary irradiation. Thorax 1987;42:77-8.

4 Ward MJ, Davies D. Pulmonary aspergilloma after radiation therapy. Br J Dis Chest 1982;76:361-4.

5 Makker H, McConnochie K, Gibbs AR. Postirradiation pulmonary fibrosis complicated by aspergilloma and bronchocentric granulomatosis. Thorax 1989;44:676-7.

6 Marcial-Rojas RA, Castro JR. Irradiation injury to elastic arteries in the course of treatment for neoplastic disease. Ann Otol 1962;71:945-58.

7 McCready RA, Hyde GL, Bivins BA, Mattingly SS, Griffen WO. Radiation induced arterial injuries. Surgery 1983; 93:306-12.

8 Bennett DE, Million RR, Ackerman LV. Bilateral radiation pneumonitis, a complication of the radiotherapy for bronchogenic carcinoma. Cancer 1969;23:1001-18. 